\title{
Mnemonic devices and natural memory
}

\author{
FRANCIS S. BELLEZZA and B. GOVERDHAN REDDY \\ Ohio University, Athens, Ohio 45701
}

\begin{abstract}
An attempt was made to make a mnemonic device, the method of loci, function more like natural memory. This was done by using familiar loci provided by the subject and by making learning incidental. After comparing the three conditions used in the experiment, it was concluded that recall of the verbal material presented to the subjects depended on the association of the loci with the words presented and also depended on the retrieval of the loci so that they could act as recall cues. The operation of natural memory seems to be similar to the method of loci for the following reasons: (1) The routine of people's lives automatically provides loci that are associated with less predictable events. (2) Perception rather than imagery associates loci with these events. (3) The accessibility in memory of familiar loci allows them to be used as retrieval cues for recent, but less predictable, episodic events.
\end{abstract}

There is currently a renewed interest among students of learning and memory in mnemonic devices (Bower, 1970). Mnemonic devices are formal schemes for remembering, and their use goes back to classical times (Yates, 1966). There are a number of different mnemonic procedures that can be used for different memory tasks (Lorayne \& Lucas, 1974), but almost all involve the use of visual imagery for creating connections or associations among words.

Because of the effort and sometimes extra training needed for the effective use of mnemonic devices, some memory theorists (Jenkins, 1974; Neisser, 1976, pp. 141-142) have suggested that the study of mnemonic devices may not contribute much to the ultimate understanding of natural memory. In the present discussion, natural memory may be considered as the incidental retention in memory of ordinary events. However, these mnemonic procedures are too effective to be quickly dismissed as irrelevant. If mnemonic devices rely on learning principles different from those of natural memory, then it may be worthwhile to know what these principles are and why they are not commonly used. If mnemonic devices and natural memory are based on the same principles, then it is not clear why special instructions are needed to induce the subjects to use mnemonic devices. Perhaps, mnemonic devices direct the user's attention to those learning processes that are most important, and, consequently, to the processes that should be most intensively studied.

The position taken in this paper is that mnemonic devices and natural memory operate in similar ways,

This research was supported in part by a grant from the Field-Wiltsie Foundation and by a grant from the Ohio University Research Committee. The authors would like to thank Ohio University Computer Services for making computer time available. Requests for reprints should be sent to Francis S. Bellezza, Department of Psychology, Ohio University, Athens, Ohio 45701. and that a mnemonic device is a procedure by which the subject can effectively remember events involving verbal material through the use of visual imagery. In the experiment described below, two steps were taken to make a mnemonic device, the method of loci, operate in a way similar to natural memory: (1) The subject was not aware that he was learning the list of words that were presented. (2) The loci used were drawn from locations that the subject experienced daily (Bower, 1970) and were not laboriously learned peg words (Miller, Galanter, \& Pribram, 1960) or locations from a public building (Yates, 1966). Two control conditions were also included in the experiment. The unfamiliar-cues condition was added to determine if an unfamiliar series of loci were also effective in incidental learning, and a no-cues condition was used to insure that learning was the result of cuing by the loci and not the result of other factors such as serial learning.

\section{METHOD}

\section{Subjects}

The subjects were 72 volunteers from introductory courses in psychology at Ohio University. The subjects received extra course credit for their participation in the experiment.

\section{Procedure}

There were 24 subjects in each of the three experimental conditions. The subjects were tested individually, and when each arrived for the experiment, he was randomly assigned to one of the incomplete conditions. All subjects were informed that the purpose of the experiment was to test their visual imagery and imagination. Nothing was said about a test of recall until the end of the experiment.

Familiar-cues condition. Each subject in this condition was asked to write down 20 distinct locations that he would pass when walking from his local address to the psychology department (Bower \& Reitman, 1972). All these locations were to be easily imaged visually. The subjects were given some examples of what was wanted.

In the second part of the experiment, each subject was instructed in the use of a 7-point scale of vividness of visual 
imagery. Three points on this scale were labeled as follows: 1 means that the image is very weak and almost does not exist; 4 means that the image is faint, but distinctly there; 7 means that the image is very strong and vivid. Next, 20 words were presented one at a time with each word printed on an index card. These words were randomly sampled from the Paivio, Yuille, and Madigan (1968) norms and had concreteness ratings from 6.50 to 7.00. The subject was instructed to form a composite image of each presented word and the corresponding location from his list of 20 loci. For example, if the first word presented was "banana" and the first location on the list was "stairway," the subject might image a large banana standing in the stairway to his apartment. The list of 20 loci were available to the subject for his use during this part of the experiment. After forming the composite image, the subject rated the vividness of that image on the 7-point imagery scale. The subject was given $10 \mathrm{sec}$ to form and rate each composite image.

After an interpolated task of counting backward by sevens for $1 \mathrm{~min}$, the subject was given a surprise test of recall. The list of loci and ratings of the composite images were removed and the subject was asked to write down as many of the 20 presented words as possible. Each subject was also instructed to try to write down the words in their order of presentation and to use any loci that could be remembered as recall cues. This test of free recall was followed by a test of cued recall, in which the subject was given the list containing his 20 loci and was again asked to write down the presented words.

Unfamiliar-cues condition. The subjects in this condition were not asked to provide their own loci, but instead were provided with 20 locations in a story describing a visit to a foreign city called Newopolis (see Appendix). The subjects were given the story to read, and within the story were 20 numbered locations. These locations were also listed on a separate sheet of paper, and the subject was instructed to try to visually image these locations as he came to each one in the story.

The procedures in the second and third parts of this condition were the same as the procedures in the familiar-cues condition except that the subject formed and rated visual images that were made up of each presented word and a location from the story rather than a location the subject generated himself. Also, in the test of cued recall that followed free recall of the presented words, the story loci were used as cues.

No-cues condition. The subjects in this condition were tested to determine how much of the recall resulted from merely forming visual images of the presented words. It could be that forming composite images of recall cues and presented words is not critical in this experiment. In previous experiments, however, the forming of the composite image has been important (Bower, 1972a). The procedure in the first part of this condition was identical to that of the familiar-cues condition; that is, the subjects had to write down 20 familiar loci. However, in the second part of the experiment, each subject was asked to form a visual image for only the presented word and then to rate this image on the 7-point scale. Although the subjects had the list of their loci in front of them, they were not asked to associate each locus with a presented word. The free and cued recall procedures performed in the third part of the experiment were the same as those used in the other two conditions.

\footnotetext{
Analysis

A 3 by 2 by 4 analysis of variance was performed on the proportion of words recalled with the factors being condition (familiar cues, unfamiliar cues, no cues), type of recall (free, cued), and serial position (list quarter), respectively. Only condition was a between-subjects factor. Also, a similar 3 by 4 analysis of variance was performed on the 20 imagery ratings. The alpha value used for all tests of statistical significance was .05 .
}

Table 1

Proportion of Words Recalled in Free and Cued Recall in the Three Experimental Conditions

\begin{tabular}{lcc}
\hline & \multicolumn{2}{c}{ Recall } \\
\cline { 2 - 3 } Condition & Free & Cued \\
\hline Familiar Cues & .83 & .89 \\
Unfamiliar Cues & .67 & .84 \\
No Cues & .47 & .49 \\
\hline
\end{tabular}

\section{RESULTS}

The recall performance of the subjects in each condition is shown in Table 1. Condition was significant $[\mathrm{F}(2,64)=95.80, \mathrm{MSe}=.62]$. Posttests using Tukey's HSD procedure (Kirk, 1968) showed that the familiarcues group recalled significantly more than did the unfamiliar-cues group. The unfamiliar-cues group, in turn, recalled significantly more than did the no-cues group. Type of recall was significant $[F(1,69)=73.18$, $\mathrm{MSe}=.013]$. As expected, cued recall performance was significantly better than was free recall performance. Serial position was also significant $[F(3,207)=9.55$, $\mathrm{MSe}=.065]$, with the serial position curve exhibiting a marked primacy effect. The proportion of words recalled from each quarter of the list was $.79, .64$, .68 , and .68 . The only other significant source of variation was the Condition by Type of Recall interaction $[\mathrm{F}(2,69)=22.88, \mathrm{MSe}=.013]$. As shown in Table 1, cued recall performance was not much better than free recall performance for the familiar-cues group, although this difference was significant using a Cicchetti (1972) test modified for a mixed design. However, cued recall was substantially better than free recall for the unfamiliar-cues group and was not significantly different from the cued recall of the familiar-cues group. Free recall and cued recall were the poorest for the no-cues group and were not significantly different.

An analysis of the imagery rating showed only condition to be a significant factor $[\mathrm{F}(2,69)=3.60$, $\mathrm{MSe}=3.29]$. The mean imagery ratings in the familiar-, unfamiliar-, and no-cues conditions were $4.11,4.44$, and 4.81, respectively. A Tukey HSD test (Kirk, 1968) showed only that the mean rating for the familiar-cues condition was significantly less than the mean rating for the no-cues condition.

\section{DISCUSSION}

The results were clear with respect to the two main points tested: (1) The subject does not have to try to learn in order for effective learning and retention to take place. (2) The use of a familiar series of loci leads to better free recall performance than does the use of an unfamiliar set of loci. However, this difference disappeared when all the loci were made available to the subjects during cued recall. A third, unpredicted, result was that images formed only of the presented words by the no-cues group were rated significantly more vivid than the composite images of the other two groups. However, this group 
had the poorest free and cued recall performance because there were no loci to function as retrieval cues.

Bower (1972b) has outlined three distinct steps that are necessary for a peg-word mnemonic to be effective. Because the peg-word mnemonic and the method of loci function in similar ways (Bower \& Reitman, 1972), these three steps apply as well to the method of loci: (1) The subject has a definite learning strategy. (2) The subject uses visual imagery to integrate the referents of the locus and of the presented word into a composite image. (3) The subject has a systematic retrieval plan. It may be worthwhile to determine how well each of these three requirements is satisfied not only in the three conditions of the experiment but also in everyday learning and remembering of events.

The first requirement does not seem to be necessary. The subjects in the familiar-cues condition free recalled .83 of the presented words under incidental learning conditions. Similarly, people are often able to recall a great deal of what they ordinarily experience without having a definite learning strategy.

The second requirement is that visual imagery is needed to associate the cue words with the presented words. Visual imagery was important in this experiment and seems to be important in the use of all mnemonic devices (Bower, 1970; Lorayne \& Lucas, 1974). The reason for this seems to be that sets of verbal materials must be encoded with respect to the things they represent in order to be best remembered. Perceptions of things seem to be more easily retained in memory than perceptions of verbal symbols. The human organism is able to overcome this situation by retrieving perceptual information from memory to transform and thus better remember the symbols he is presented. Even when linguistic elaboration is used to encode verbal symbols, collateral visual imagery may be taking place (Bellezza, Poplawsky, \& Aronovsky, 1977; Paivio, 1971, Chapter 11). In natural memory for events, visual imagery is usually not needed because visual perception is taking place and automatically integrating the contiguously occurring events. Even in experimental situations, learning is generally better if objects or pictures of objects are used as the items rather than their names (Paivio, 1971). If a person perceives a large banana, or something even less unusual, standing on his stairway, he is likely to remember that event when he again sees or thinks of the stairway.

The third requirement of having an effective retrieval scheme was important in the conditions of the experiment. Familiar locations were more effective in free recall compared to unfamiliar locations, only because the subjects could more easily generate the familiar locations as cues. When all the loci were provided to the subjects, familiar and unfamiliar loci were no different in cuing the words that were to be remembered. Hence, the subjects were able to recreate the conditions under which the presented words were processed (Bellezza, Cheesman, \& Reddy, 1977; Tulving \& Thomson, 1973). Retrieval cues for remembering under ordinary conditions can be provided by the routine of a person's life, which usually involves repeated daily, weekly, and seasonal cycles of experience. The familiar and predictable routine and accompanying perceptions form a background or stage for the less predictable events. If some events are to be recalled, such as the names of people spoken to on a previous day, a person can mentally review what his routine would be for that particular day and the accompanying visual images can act as retrieval cues for those recent experiences that were not routine and predictable. The interference in memory among events that occur at similar times and places may be similar to the interference among words associated with the same locus using a mnemonic device (Bower \& Reitman, 1972). The daily, weekly, and seasonal routine of the average person's life provides what Bartlett (1932, Chapter 10) calls a schema or organized setting for the experienced events. If the appropriate schema can later be retrieved, then the person will be more likely to recall the events most recently associated with it.
In summary, the position taken here is that in natural memory "perception of things" frequently occurs and results in incidental retention of events. The cyclic and routine experiences of most people's lives provide a background for these events and can later act as retrieval cues. When more symbolic information is presented, such as words, perceptual information relating to the referents of these symbols must be retrieved from memory in order to encode and better remember these symbols. Mnemonic devices guarantee that the subject encodes verbal material in this way by using visual imagery and also guarantees that the subject has an organized retrieval scheme for these encodings.

It seems that symbols are not as easily remembered as are things after they are perceived. The possible reasons for this such as familiarity, distinctiveness, meaningfulness, and so on are still under investigation in psychology.

\section{Appendix}

A Visit to Newopolis

We arrived at Newopolis by riding a (1) riverboat up a beautiful tropical (2) river covered with water lilies. After a journey of about $3 \mathrm{~h}$, we docked at a (3) coffee plantation. As we left the boat, workers were busily loading the boat with bags of coffee from large (4) warehouses.

In the distance we could see the (5) large stone gate of Newopolis. (6) Street vendors of all sorts were milling about in front of the gate selling food, clothing, jewelry, and even live animals! There were also many (7) soldiers standing about with large white feathers in their helmets. Some were boarding the railroad cars at the (8) railroad terminal right next to the city gate.

Right inside the gate of Newopolis were the city's gardens. There were beautiful (9) chestnut trees with many (10) squirrels running between them. Large plots of (11) flowers lined the sidewalks. Citizens of Newopolis sat on the many (12) benches in order to admire the gardens.

In the middle of Newopolis was the (13) city hall which had many murals inside depicting Newopolis' history. The largest office in the city hall was the (14) mayor's office. The mayor greeted us and took us to the (15) police station, where we were to be assigned a chauffeur. The mayor also offered to show us the (16) jail, but unfortunately he did not have the time to do so.

Newopolis has a very well known (17) concert hall with large (18) billboards in front of it announcing what great artists would be performing there. It also has a well known (19) art gallery which contains a large collection of prehistoric scuptures. These (20) sculptures are famous throughout the world.

\section{REFERENCES}

Bartlett, F. C. Remembering: A study in experimental and social psychology. Cambridge, England: Cambridge University Press, 1932.

Bellezza, F. S., Cheesman, F. L., \& Reddy, B. G. Organization and semantic elaboration in free recall. Journal of Experimental Psychology: Human Learning and Memory, 1977, 3, 539-550.

Bellezza, F. S., Poplawsky, A. J., \& Aronovsky, L. A. The functional role of one-word mediators. Bulletin of the Psychonomic Society, 1977, 10, 460-462.

Bower, G. H. Analysis of an mnemonic device. American Scientist, 1970, 58, 496-510.

Bower, G. H. Mental imagery and associative learning. In L. W. Gregg (Ed.), Cognition in learning and memory. New York: Wiley, 1972. (a)

BowER, G. H. A selective review of organizational factors in memory. In E. Tulving \& W. Donaldson (Eds.), Organization of memory. New York: Academic Press, 1972. (b) 
Bower, G. H., \& ReItman, J. S. Mnemonic elaboration in multilist learning. Journal of Verbal Learning and Verbal Behavior, 1972, 11, 478-485.

Cicchetri, D. V. Extension of multiple-range tests to interaction tables in the analysis of variance: $A$ rapid approximate solution. Psychological Bulletin, 1972, 77, 405-408.

JENkINS, J. J. Can we have a meaningful theory of memory? In R. L. Solso (Ed.), Theories in cognitive psychology. Potomac, Md: Lawrence Erlbaum, 1974.

KIRK, R. E. Experimental design procedures for the behavioral sciences. Belmont, Calif: Wadsworth, 1968.

LORAYNe, H., \& LuCAS, J. The memory book. New York: Ballantine, 1974.

Miller, G. A., Galanter, E., \& Pribram, K. H. Plans and the structure of behavior. New York: Holt, Rinehart, \& Winston, 1960.
NeIsser, U. Cognition and reality. San Francisco: Freeman, 1976. PaIvio, A. Imagery and verbal processing. New York: Holt, Rinehart, \& Winston, 1971.

Paivio, A., Yuille, J. C., \& Madigan, S. A. Concreteness, imagery, and meaningfulness values for 925 nouns. Journal of Experimental Psychology Monograph, 1968, 76(1, Part 2).

Tulving, E., \& Thomson, D. M. Encoding specificity and retrieval processes in episodic memory. Psychological Review, 1973, 80, 352-373.

YATES, F. A. The art of memory. London: Routledge \& Kegan Paul, 1966.

(Received for publication January $14,1978$. 